\title{
Aplicação de metodologias de aprendizagem ativa em um curso de Engenharia Elétrica durante a pandemia da COVID-19: sala de aula invertida, gamificação e PBL
}

DOI: 10.37702/2175-957X.COBENGE.2021.3617

Jhennifer Freitas dos Santos - jhennifer.santos@itec.ufpa.br

Universidade Federal o Pará passagem isabel, entre passagem das flores e passagem brotinho 951 66113-240 - Belém - PA

Bendict Katukula Tshoombe - bendict.rugby@gmail.com Universidade Federal o Pará Alameda moreira da costa 15 66093-710 - Belem - PA

WELLINGTON DA SILVA FONSECA - fonseca.ufpa@gmail.com Universidade Federal o Pará

RUA Oito 42

67020-460 - Ananindeua - PA

Resumo: Este artigo é de natureza qualitativa e quantitativa e apresenta a perspectiva dos alunos quanto ao plano de ensino adotado na disciplina de materiais elétricos do curso de Engenharia Elétrica no período de Ensino Remoto Emergencial (ERE) da Universidade Federal do Pará (UFPA), onde a coleta desses relatos ocorreu por meio de questionário aplicado no final da matéria. Foram utilizadas metodologias como sala de aula invertida vinculada à gamificação, além de simulações computacionais. Os recursos utilizados para o desenvolvimento das atividades propostas foram videoaulas compartilhadas previamente com os alunos, aplicando assim os conceitos de sala de aula invertida, a plataforma Kahoot, que permitiu a criação de um quiz para a gamificação das atividades e o uso de um software de simulação eletromagnética para aplicação do método de Aprendizagem Baseada em Projetos (PBL). Além disso, este estudo também destaca o potencial desse modelo de ensino e mostra que a aplicação dessas metodologias são válidas e amenizam alguns problemas enfrentados pelos alunos durante o período de pandemia ocasionado pela COVID-19. 


\section{COBENCE \\ $2021 \begin{aligned} & \text { eIV Simpósio Internacional } \\ & \text { de Educação em Engenharia } \\ & \text { da ABENGE }\end{aligned}$ 28 a 30 de SETEMBRO \\ Formação em Engenharia: Tecnologia, Inovaçăo e Sustentabilidade"}

Palavras-chave: sala de aula invertida, gamificação, simulação, PBL, Kahoot. 


\section{Aplicação de metodologias de aprendizagem ativa em um curso de Engenharia Elétrica durante a pandemia da COVID-19: sala de aula invertida, gamificação e PBL}

\section{INTRODUÇÃO}

No Brasil, o ano de 2020 foi marcado por diversos desafios ocasionados pela pandemia da COVID-19, um deles foi na área educacional devido às medidas de isolamento social adotadas pelo Governo Federal. A portaria № 343 publicada no Diário Oficial da União pelo Ministério da Educação determinou a suspensão das aulas presenciais e a adoção de recursos digitais como meio de ensino para o período de enfrentamento da pandemia. Para cumprir essa determinação, a Universidade Federal do Pará (UFPA) e outras Instituições Federais adotaram o Ensino Remoto Emergencial (ERE) que segundo a Behar (2020), entende-se como uma modalidade de ensino provisória em que o docente está demograficamente distante dos seus alunos.

O ERE se tornou o meio alternativo adotado por essas instituições para suprir a ausência da convivência entre alunos e professores, além da continuidade do calendário acadêmico. Essa metodologia de ensino é dividida em dois momentos, o primeiro momento são as atividades assíncronas, onde são repassadas videoaulas, listas de exercícios ou trabalhos de pesquisa, e o segundo momento são os encontros síncronos que possibilitam a comunicação ativa entre docentes e discentes. Nesse segundo momento surge um novo modelo de interação conhecido como "presença social". Esse termo expõe a maneira de como se dá a relação humana no ambiente tecnológico (COELHO, 2019 apud LOWENTHAL, 2010).

Esse ensino ocorre por meio do Ambiente Virtual de Aprendizagem (AVA) com o auxílio das Tecnologias de Informação e Comunicação (TICs) que segundo a Organização das Nações Unidas para Educação, Ciência e Cultura (UNESCO) possibilitam ao docente, quando utilizado corretamente, promover aos alunos o desenvolvimento de competências comunicativas (UNESCO, 2009). Entretanto, para isso, esses profissionais devem apresentar qualificações necessárias para o manuseio dessas ferramentas aliado a didáticas adaptadas para essa modalidade de ensino, pois o público-alvo que deve ser atingido possui uma grande convivência com esses recursos.

Segundo Prado (2015), às características apresentadas pelos discentes do ensino superior são a aptidão com o uso de TICs, a capacidade e facilidade de desenvolver várias atividades simultaneamente, além da inconstância em manter o foco e o constante bombardeamento de informação faz com que acreditem que são detentores de todo o conhecimento. Sendo assim, não basta transpor o conteúdo ensinado presencialmente para o meio tecnológico sem a reinvenção das estratégias, pois o que determina a aprendizagem é a metodologia utilizada e não apenas os recursos tecnológicos (Duarte2020).

Assim, este trabalho apresenta uma a análise da percepção dos discentes de uma estratégia metodológica baseada em estratégias de aprendizagem ativa, no caso, a sala de aula invertida, a gamificação e a Aprendizagem Baseada em Projetos (PBL) em turmas do Curso de Engenharia Elétrica. Essas metodologias, foram utilizadas juntamente com uma das tecnologias da Indústria 4.0, a simulação, em busca superar e mitigar os impactos impostos pela pandemia do COVID -19 no ensino superior. Assim, foi possível proporcionar aos discentes a vivência do comportamento dos fenômenos eletromagnéticos e a autonomia na busca do aperfeiçoamento dos conceitos básicos da disciplina. 


\section{PROBLEMÁTICA E MOTIVAÇÕES}

Sabe-se que os cursos de engenharias necessitam de muitas aulas teóricas (em sala de aula) e aulas práticas (em laboratórios), para preparar os futuros engenheiros a solucionar possíveis adversidades em situações reais. Infelizmente, essas aulas se tornaram inviáveis de serem realizadas no atual cenário de pandemia que está se vivendo. Assim, além do déficit da ausência das aulas presenciais, os docentes estão enfrentando também outras problemáticas, como terem que modelar seu plano de ensino em momentos mais dinâmicos e a necessidade de simular a realidade no meio virtual. Nesse contexto, o uso de TIC's, estratégias de aprendizagem (como, por exemplo, sala investida, gamificação e PBL) e softwares de simulações, são algumas das ferramentas que podem ser utilizadas no chamado "Novo Normal" do cotidiano educacional universitário para amenizar as problemáticas supracitadas. Assim, como forma de ultrapassar essas barreiras a disciplina de materiais elétricos de uma turma de Engenharia Elétrica da UFPA utilizou em suas aulas durante o ERE, TIC's, metodologias de aprendizagem (sala investida, gamificação e PBL) e o software de simulação open source chamado de Finite Element Method Magnetics (FEMM), tendo como principal motivação preencher um pouco a lacuna criada pela ausência das aulas presenciais.

O FEMM é um instrumento que propicia a obtenção e visualização dos efeitos eletromagnéticos nos materiais. Esse software possibilita aos alunos observar e medir campos eletromagnéticos de formas que seriam difíceis ou impossíveis até mesmo em aulas laboratoriais (STOEV, 2017). O FEMM é baseado no Método dos Elementos Finitos (MEF) que é uma técnica computacional usada para obter soluções aproximadas dos problemas de valores de contorno na engenharia. Sucintamente, o MEF permite que um domínio seja discretizado em um número finito de partes (ou elementos) e enfatiza que as características do domínio contínuo podem ser estimadas pela montagem de propriedades semelhantes de elementos discretizados por nó (HUTTON, 2004). Deve-se mencionar que este trabalho não se concentrou tanto no modelo matemático do $\mathrm{MEF}$, pois está além do escopo do estudo da disciplina de materiais elétricos.

$\mathrm{Na}$ literatura, é possível encontrar diversos estudos relacionados com a aplicação do MEF na área de engenharia elétrica. Em Preis et al. (2006), realiza-se uma análise de acoplamento térmico-eletromagnético de transformadores de potência a fim de verificar a influência do campo magnético e das propriedades dos materiais na temperatura do equipamento. Em José et al. (2019) foi realizado o sensoriamento do motor de indução, onde os dados de corrente e temperatura são enviados para o software FEMM, que através de métodos finitos, realiza a análise eletromagnética e térmica. Em Fonseca et al. (2018), é realizada uma análise magnética-estrutural para verificar o efeito de estresse mecânico nos enrolamentos de um transformador de 50MVA em condições de inrush (partida) utilizando o MEF.

Nesta perspectiva, segundo Veloso (2013), os centros de pesquisa e as indústrias mundiais carecem de mão de obra qualificada que saiba utilizar ferramentas de MEF. A realidade brasileira não foge a essa regra. Barrios (2007) afirma que, geralmente, as empresas precisam capacitar seus profissionais para o manuseio desse recurso. Assim, outra motivação para a utilização o software FEMM é colocar os alunos em contato com os programas de simulação e fornecer a eles com um certo nível de entendimento sobre essa ferramenta para prepará-los para o mercado de trabalho. 


\section{METODOLOGIAS DE APRENDIZAGEM ATIVA}

A aprendizagem ativa consiste em protagonizar o estudante no procedimento de ensino e aprendizagem (LEITE,2018), e na aplicação de meios em que o docente se torna um mediador e não mais o centro desse cenário. Nesse contexto, foi adotada na disciplina de materiais elétricos da UFPA as metodologias explicadas nos tópicos abaixo com o intuito de aplicar as estratégias de aprendizagem ativa.

\subsection{Sala de Aula Invertida}

Nesse contexto, planos de ensino baseados em aprendizagem ativa ganham cada vez mais espaço entre os profissionais da educação. A exemplo disso, tem-se a sala de aula invertida (Flipped Classroom) que é uma importante ferramenta para dinamização das aulas. Essa metodologia foi pensada por Bergmann e Sams (2016), e segundo Fonseca (2017) a sala de aula invertida pode ser entendida como um modelo pedagógico em que o conteúdo é estudado antes da aula presencial. Dessa forma, a sala de aula passa a ser uma oportunidade para discutir, experimentar e solucionar dúvidas, e não mais o momento em que se recebe informações.

Nessa forma de ensino, o professor, antes das aulas, propõe os assuntos conceituais aos alunos e esses por sua vez se tornam os responsáveis por buscar informações básicas sobre esses temas, seja por artigos acadêmicos, livros, videoaulas na internet ou disponibilizadas pelo docente (GARBIN, 2020 apud MORAN, 2015). Essa característica de ensino proporciona o uso das TIC's e AVA, pois é um meio acessível que reúne todas essas fontes de informação e consequentemente facilita o entendimento desses discentes que já possuem a práxis com dispositivos digitais.

\subsection{Gamificação}

Uma prática potencializadora dos benefícios da sala de aula invertida e a gamificação (gamification) nos momentos interativos entre os alunos e o professor. $O$ pioneiro a utilizar esse termo foi o programador britânico Nick Pelling em 2002. A gamificação consiste na utilização de jogos que visam instigar o público-alvo a solucionar problemáticas reais (MENEZES, 2018). Para Nascimento (2019, apud KAPP, 2012), essa dinâmica deve envolver todos os recursos digitais que apresentarem características adequadas para o ambiente estudantil e que não foque apenas nas pontuações e recompensas, mas sim estimule os alunos a desenvolverem competências úteis para sua vida acadêmica. Essa metodologia é utilizada para sair do modelo passivo de ensino para um modelo mais dinâmico, ativo e atraente que instigue o estudante e promova a aprendizagem que é o objetivo principal de qualquer professor.

Aliar essas ferramentas ao plano de ensino favorece, não apenas os estudantes, mas também aos professores. Para os discentes de engenharia essa agregação auxilia em seu entendimento do assunto, pois esses são requisitados a desenvolver raciocínios extremamente abstratos em determinadas atividades individuais o que, muitas vezes, não traz resultados cognitivos desejáveis e pode prejudicá-los em suas carreiras profissionais, visto que a realização desses exercícios é realizada sem uma das peças mais importante do ensino que é o professor.

Já para o docente da essa associação metodológica permite a ele suprir esse déficit dos seus alunos, visto que a parte mais difícil e complexa pode ser ministrada e orientada por ele em razão do aluno está familiarizado com os temas que serão abordados durante as aulas. Dessa forma, ocorre a otimização do tempo da explicação teórica proporcionando um maior tempo de interação entre educador e educando o que consequentemente desenvolve todas as habilidades que esses futuros profissionais precisam ter para ingressar 
no mercado de trabalho ou continuar a vida acadêmica. Além disso, por ser uma metodologia flexível pode ser implementada remotamente por meio de recursos digitais, encaixando-se perfeitamente no período extraordinário em que estamos vivendo, onde a tecnologia é um dos principais meios de comunicação.

\subsection{Aprendizagem Baseada em Projetos}

A metodologia de ensino PBL, do inglês Problem Based Learning, propõe que a capacitação e aprendizagem dos estudantes será proveitosa em um maior grau se os problemas propostos para serem solucionados durante a instrução forem contextualizados intimamente à realidade que os alunos encontrarão após a sua formação. De acordo com Fonseca (2016) e a Anabuki (2017), essa metodologia é baseada no aluno como o centro do ensino e o professor como guia nesse processo, em que diferentes tipos de problemas são usados para a aprendizagem dos conteúdos e o desenvolvimento de aptidões e competências dos alunos em contexto de sala de aula. Assim, para uma dada disciplina, um conjunto problemas são levantados e esses problemas devem ser abrangentes, interdisciplinares e ter relação com o seu conteúdo programático da disciplina em questão. Além disso, os alunos são divididos em pequenos grupos, sob a supervisão de um tutor, e são motivados a buscar os conhecimentos necessários à resolução dos problemas (OLIVEIRA 2017).Este conceito de PBL se torna de grande relevância na engenharia especialmente com as inúmeras aplicações da Quarta Revolução Industrial, também chamada de Indústria 4.0. Um dos imperativos dessa Quarta revolução é o aumento e a capacitação do capital humano, o que possibilita uma maior independência e democratização do conhecimento, aproximando-a do principal objetivo da Educação 4.0 que é fazer com que todas as pessoas tenham acesso e sejam capazes de ir ao encontro do conhecimento e das competências necessárias para que possam inovar e produzir(CAMPOS et al 2019). Dessa maneira, a Educação 4.0 é focada no aperfeiçoamento do aprendizado para que o processo de inovação seja mais frequente e igualitário. Além disso, é importante que seja ressaltado que esses aprimoramentos, em particular os tecnológicos, são paralelos e proporcionais às mudanças das características das novas gerações (CAMPOS et al 2019).

\section{METODOLOGIA}

Foi realizada uma pesquisa de caráter quanti-qualitativa e aplicada nos discentes da disciplina de materiais elétricos do curso de engenharia elétrica da UFPA - Campus Belém durante os períodos de ERE adotado pela universidade. Até agora, a UFPA já realizou dois períodos de ERE, sendo eles, o ERE1 do período de 5 de outubro à 5 de dezembro 2020 e o ERE2 entre os meses de janeiro e fevereiro de 2021. Para coleta de dados, foi disponibilizado à turma, ao final do curso, um questionário na plataforma Google Forms. De acordo com Chaer et al. (2011) o questionário "possibilita atingir grande número de pessoas, mesmo que estejam dispersas numa área geográfica muito extensa". Dessa forma, sendo o melhor meio de reunir as percepções da turma já que estamos passando pelo isolamento social.

Esse questionário avaliativo foi dividido em três seções. A primeira tinha como objetivo diagnosticar a aprendizagem dos alunos sobre os assuntos abordados, saber se instigou eles a se aprofundarem mais nos temas e se conheciam e achavam válidas as metodologias e as atividades implementadas durantes as aulas. A segunda seção era voltada para entender se os recursos digitais utilizados favoreciam o seu desempenho na disciplina e na sua formação acadêmica, se possuíam dificuldades relacionadas a essas 
ferramentas e quais eram elas. Na terceira seção foi focada em melhorias do plano de ensino da matéria. Nela os alunos foram solicitados a destacar os pontos positivos da disciplina, além de deixar suas sugestões e críticas.

O conteúdo programático dessa disciplina foi ensinado dispondo do software FEMM, da metodologia de sala de aula invertida e gamificação seguindo os moldes do ERE. Nesse contexto nos momentos assíncronos eram disponibilizadas videoaulas com duração de no máximo 40 minutos expondo toda a parte teórica dos assuntos do curso, resolução de exercícios, além de tutoriais de simulação no FEMM.

Esses tutoriais focaram em explicar como importar as geometrias dos objetos elétricos para simulação e inserir os materiais compostos por eles, adicionar as condições de contorno e a corrente elétrica que passar por eles, gerar a malha e extrair resultados dessas simulações. Os alunos tiveram que analisar a densidade do fluxo magnético, as perdas resistivas bem como o torque do motor elétrico de indução. Abaixo, Figura 1 mostra a geometria e densidade de fluxo magnético do motor requerido para simulação de um tutorial que foi desenvolvido pelo Meeker (2015), e utilizado em uma das aulas. Esse tutorial pode ser encontrado em: https://www.femm.info/wiki/InductionMotorExample.

Figura 1 - Densidade de fluxo magnético do motor de indução no tutorial.
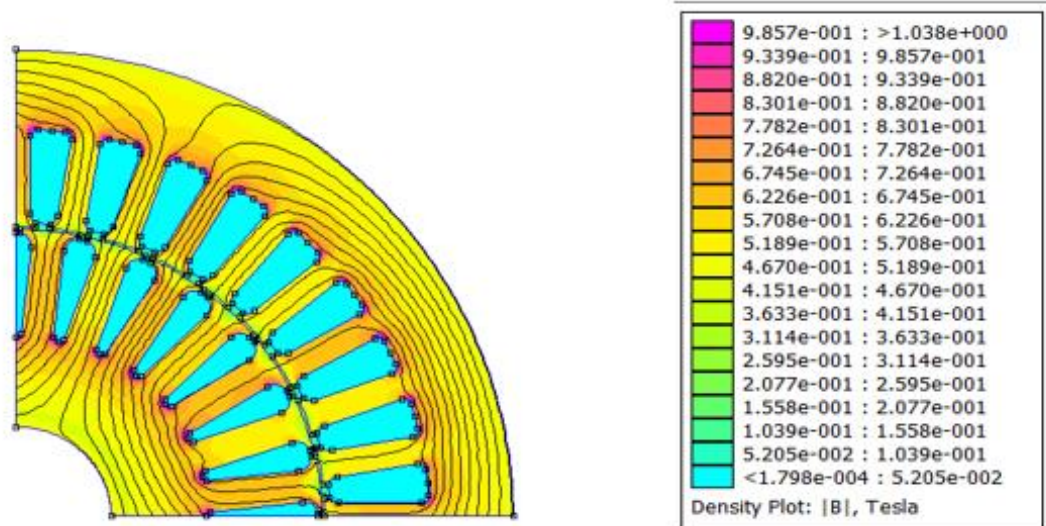

Fonte: Autor.

Um destaque é que diferente da aula convencional onde apenas calculam o resultado analiticamente, FEMM permite visualizar esses resultados, possibilitando um melhor entendimento dos conceitos de caracterização eletromagnética de máquinas elétricas. Nos encontros síncronos era utilizado o método da gamificação, através de um quiz no programa Kahoot Esse programa que possibilita ao docente criar quiz com assuntos da disciplina e acompanhar o desempenho dos discentes (SANDE \& SANDE 2018). Assim, foram inseridas no Kahoot questões referentes aos assuntos abordados nas aulas anteriormente compartilhadas e no foi possível somar os pontos da média final dos alunos no quiz. As resoluções de cada questão do quiz eram comentadas pelo professor com o objetivo de elucidar possíveis dúvidas que surgiam nos alunos em seus estudos sozinhos. Para essa dinâmica foi proposto a formação de grupos de no máximo 5 pessoas, onde as equipes pontuavam apenas quando um de seus integrantes estivesse no pódio, ou seja, entre os três primeiros colocados no quiz. Essa pontuação era diferente em cada colocação, 0 aluno que ficasse em primeiro lugar receberia 3 pontos para a sua equipe, o segundo lugar ganhava 2 pontos e o terceiro apenas 1 ponto.

O plano de atividades avaliativas seguiu um cronograma que possuía três etapas. A primeira consistia em duas provas individuais que avaliavam a aprendizagem dos alunos 
referentes aos assuntos teóricos abordados durante a disciplina. Para a execução da segunda e terceira etapa foram utilizados os grupos formados na dinâmica do quiz. A segunda etapa foi desenvolvida por meio de um seminário sobre temas escolhidos em um sorteio randômico. Os temas do seminário foram escolhidos de forma que os alunos aprendessem e conhecessem as aplicações industriais dos materiais elétricos apresentados durante as aulas.

A terceira etapa foi composta pela produção de um artigo científico com o modelo de formatação dos trabalhos submetidos no COBENGE (Congresso Brasileiro de Educação em Engenharia) onde o tema a ser abordado foi a simulação dos motores de carros elétricos. Essa etapa tinha como objetivo mostrar a aplicação do software FEMM que segundo Sadiku (1991) nem sempre os conceitos introdutórios e básicos de MEF são de simples assimilação, sendo interessante trazer esse conhecimento aos graduandos de forma prática e sucinta, para que possam conhecer e entender essa ferramenta durante sua graduação, além de proporcionar uma oportunidade de conhecer o mercado de carros elétricos, que atualmente é uma área em ascensão.

\section{$5 \quad$ RESULTADOS E DISCUSSÕES}

O questionário aplicado foi dividido em três seções, conforme mencionado anteriormente, e foi respondido por 10 alunos, o que corresponde a $58 \%$ da turma. $\mathrm{Na}$ primeira seção foi solicitado que avaliassem em uma escala de 1 a 5 , sendo 1 "ruim" e 5 "ótimo" em relação ao seu grau de entendimento da disciplina, a estratégia da didática utilizada e se de uma forma geral a disciplina foi satisfatória, conforme mostra a Figura 2. Essas questões tinham como objetivo identificar se mesmo com todas as dificuldades impostas pelo ERE o plano de ensino elaborado alcançou suas metas. Como pode ser visto $70 \%$ dos alunos afirmaram que tiveram um bom entendimento, $40 \%$ avaliaram a didática como sendo ótima e cerca de $80 \%$ dos alunos avaliaram a disciplina como sendo boa.

Figura 2 - Análise geral do curso.

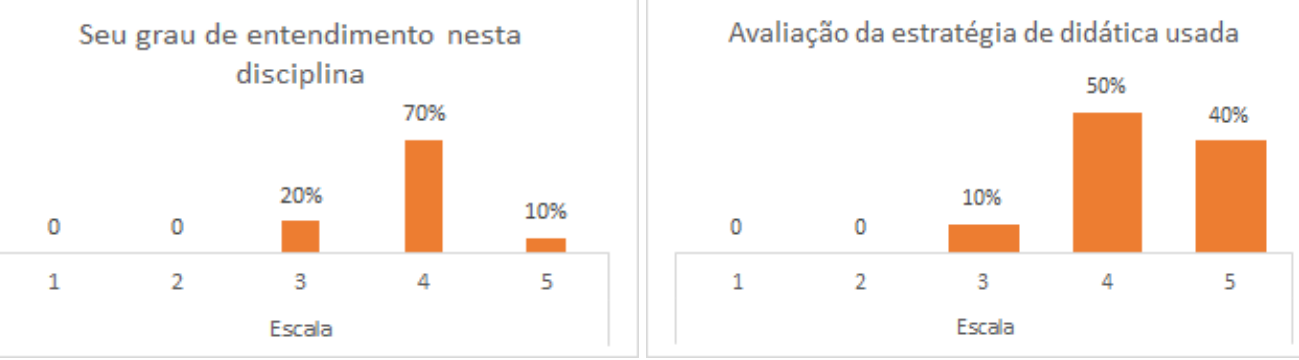

Avaliação geral da disciplina

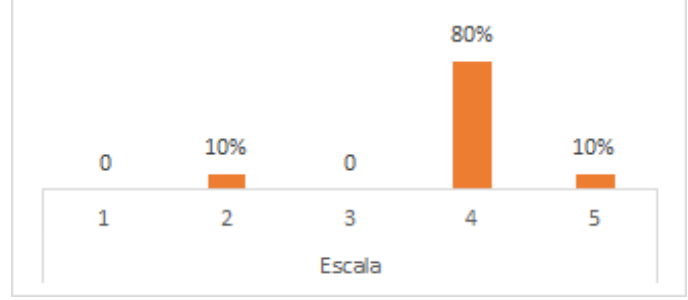

Fonte: Autor. 
Ainda nessa primeira seção os alunos foram questionados se o curso despertou neles interesses sobre assuntos abordados, se possibilitou a eles adquirirem novos conhecimentos e se oportunizou o aprendizado sobre carros elétricos. Essas questões foram adicionas porque no decorrer das atividades foi apresentado os modos como os materiais elétricos se comportam, onde eles podem ser utilizados, como verificar os fenômenos físicos presente na exposição de cada material por meio do FEMM e o funcionamento de motores elétricos. Constatou-se que a turma em sua totalidade afirmou que o curso propiciou a eles adquirirem conhecimentos novos e favoreceu o aprendizado sobre o funcionamento de carros elétricos, além disso $70 \%$ afirmaram que seu interesse sobre os temas debatidos durante o curso aumentou.

$\mathrm{Na}$ seção 2 do questionário os alunos foram questionados sobre os métodos de aprendizagem ativa utilizados. As questões tiveram como enfoque saber a familiaridade dos alunos com as metodologias adotadas: "10) Você já ouviu falar em sala de aula invertida?" e "11) Você já ouviu falar em Gamificação para Ensino?". A maioria dos discentes (70\%) afirmaram que "Sim" já conheciam a sala de aula invertida e a gamificação (60\%). Esses resultados podem ser vistos na Figura 3.

Figura 3 - Sala de aula invertida e gamificação.

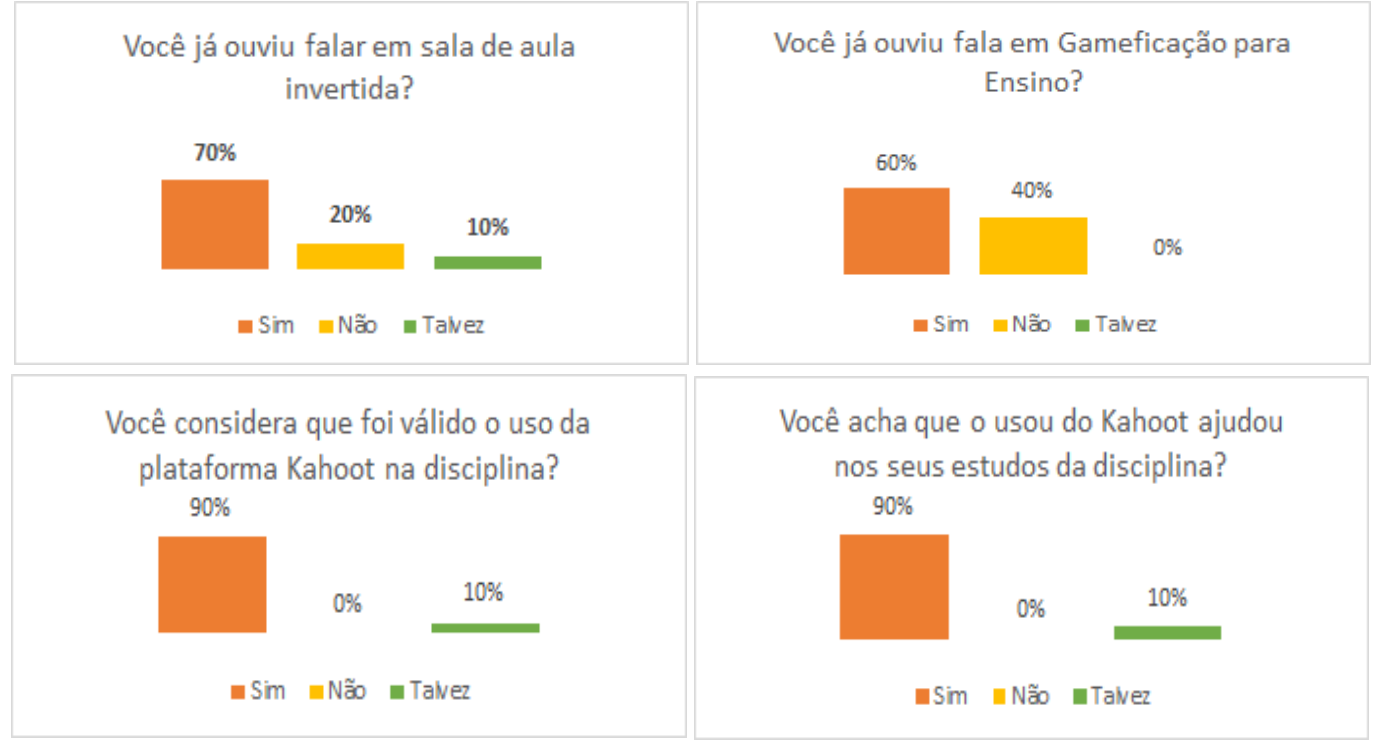

Fonte: Autor.

Ainda na Figura 3 é possível visualizar os resultados do questionário em relação a ferramenta de gamificação de ensino utilizada, o Kahoot, cerca de $90 \%$ da turma afirmou que foi válido o uso dessa plataforma e que ela ajudou nos estudos da disciplina, conforme mostra a Figura 3. Segundo a pesquisa de Pavanelo (2017) , a gamificação tem o intuito de melhorar a aprendizagem e o envolvimento dos alunos com os assuntos. Ainda nessa seção, os discentes foram perguntados sobre o software FEMM. Eles foram questionados se já haviam tido contato com o software, o que acharam do grau de facilidade da sua interface gráfica e sobre o seu uso no projeto final desenvolvido, conforme mostra a Figura 4. 
Figura 4 - Avaliação do FEMM.

Qual o grau de facilidade com a interface do software?
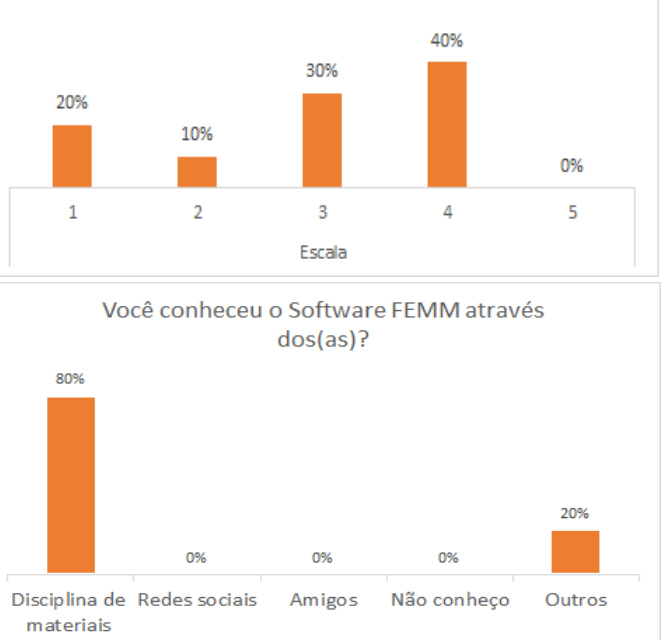

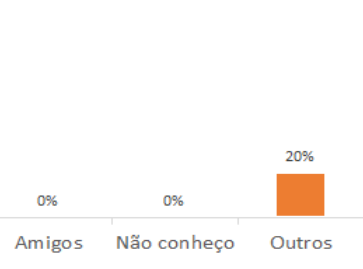

Fonte: Autor. avalie sua experiência de uso do software FEMM em seu projeto final de materiais elétricos.

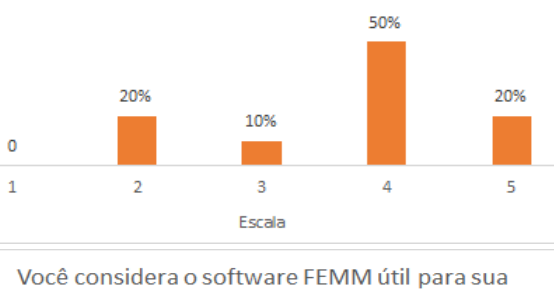
formação acadêmica?

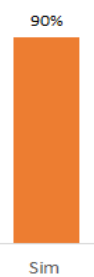

$\sin$

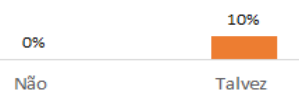

Os resultados mostram que $80 \%$ dos alunos tiveram a primeira experiência de trabalho com essa ferramenta na disciplina. Quando questionados sobre o grau de facilidade no uso do programa nenhum aluno relatou ter tido uma ótima facilidade com a interface do FEMM. Esse fato pode decorrer da falta de familiaridade com o software e porque como ele é um programa open source, por isso a sua interface pode ser menos "amigável" para aprendizagem em relação aos softwares equivalentes que são comerciais.

Ainda a respeito do FEMM, foi solicitado aos alunos que avaliassem sua experiência com o uso desse programa no seu projeto final, bem como sua opinião sobre a relevância do mesmo como ferramenta complementar nesta disciplina. Conforme mostra a Figura 4 $90 \%$ da turma considera o FEMM uma ferramenta útil para sua vida acadêmica e metade dos alunos (50\%) tiveram uma boa experiência no uso do FEMM no seu projeto final e consequentemente desenvolvesse interesse pela área de simulações. Esse resultado pode ser atribuído a orientação e suporte contínuo para o sucesso do aprendizado dos alunos neste curso por meio dos tutoriais e momentos de para retirar as dúvidas com o professor.

$\mathrm{Na}$ terceira e última seção do questionário optou-se por abrir um espaço para que os alunos pudessem expressar suas percepções sobre as metodologias utilizadas, dificuldades enfrentadas, críticas e elogios. Nesta seção a questão 1 perguntava se os alunos tinham sugestões ou dicas para melhorar a disciplina de materiais elétricos e se sim, quais eram. Os relatos dos alunos sobre esse ponto foram bem diversificados, alguns pediram mais encontros síncronos, já que a interação professor-aluno era feita apenas uma vez na semana. Esses comentários se assemelham aos resultados da pesquisa feita por Pavanelo (2017) na aplicação da metodologia de sala invertida na disciplina de cálculo 1 onde os alunos sentem falta de mais aulas expositivas especialmente na resolução de listas. Além disso, outros alunos solicitaram a revisão da distribuição de recompensa no quiz, pois segundo eles o fato de apenas a equipe com maior pontuação levar o ponto extra é injusto. Destaca-se que aluno sugeriu que haja mais interdisciplinaridade entre das atividades avaliativas, os assuntos do cotidiano e da ementa do curso de Engenharia Elétrica.

destacarem relação aos pontos positivos sobre a disciplina, a maioria destacou que a ferramenta Kahoot os estimulou a se aprofundarem no conteúdo da disciplina e os ajudou também a perceberem suas falhas nas resoluções dos exercícios. Além disso, eles 
relataram que o projeto final possibilitou a eles a visualização da aplicação dos materiais elétricos no mercado. Por fim pediu-se à turma para dizer suas críticas para o melhor desenvolvimento do curso, a maior parte da turma relatou pontos parecidos como haver mais vídeos com resolução de questões e utilizar o FEMM para criação de projetos que possam ser aplicados no cotidiano deles, como por exemplo a análise de um circuito elétrico ou uma fonte de energia.

\section{CONCLUSÃO}

Este artigo apresentou a perspectiva dos discentes quanto ao plano de ensino composto pela sala de aula invertida ou flipped classroom atrelada a gamificação, além das simulações computacionais utilizadas para a aplicação do método $P B L$ no ERE da disciplina de materiais elétricos. Essa metodologia foi desenvolvida nessa disciplina por diversos motivos entre eles a disposição do professor em buscar meios de melhorar seus métodos pedagógicos para ensinar os assuntos de maneira homogênea e encontrar um meio de continuar o cotidiano acadêmico sem prejuízos ao aprendizado dos alunos no período de pandemia devido a importância dessa disciplina no curso de Engenharia Elétrica. Observase a partir das avaliações realizadas com os alunos que a metodologia proposta atingiu seu objetivo, ao qual visava tornar a disciplina mais dinâmica, forneceu a esses alunos a descobertas de novas áreas mesmo em tempos de pandemia e motivou esses discentes no processo de ensino e aprendizagem.

ANABUKI, E. T; LOPES, L. C. G.; BARBOSA, R. F. PBL and Collaborative Learning Applied in The Course of Engineering of Control and Automation: Case Study at CEFET-MG. In International Conference on Alive Engineering Education 2017, 2017, Rio de Janeiro. ICAEEdu 2017, 2017.

Behar, Patricia. O Ensino Remoto Emergencial e a Educação a Distância. Jornal da Universidade -UFRGS. Rio Grande do SUL. Disponível em: https://www.ufrgs.br/coronavirus/base/artigo-o-ensino-remoto-emergencial-e-a-educacaoa-distancia/. Acesso em: 18 abr. 2021.

BERGMANN, Jonathan; SAMS, Aaron. Sala de Aula Invertida: uma metodologia ativa de aprendizagem. Rio de Janeiro: LTC, 2016.

Borges. W. R., Sousa, A. R. M., Lobato E. P. S. Indústria 4.0: Aplicação experimental em motor de indução monofásico. ENGENHARIA NO SÉCULO XXI,vol. 15 ,no. 1, pp. 34 -39, 2020.

CAMPOS,L. C.;NEVES, R. M.;FORMENTO, A.;CAMPOS, B. C. O.; et al. A educação em engenharia no context da quarta revolução industrial. In: XLIV Congresso Brasileiro de Educação em Engenharia (COBENGE) 2019.

CHAER, G. A técnica do questionário na pesquisa educacional. Evidência, Araxá, v. 7, n.7, p.251- 266, 2011.

Coelho, W.;Tedesco, P. A percepção do outro no ambiente virtual de aprendizagem: presença social e suas implicações para Educação a Distância. Revista Brasileira de Educação, Curitiba, v.22, n.70, 2019.

Duarte, Kamille A.;Medeiros, Laiana M. Desafios dos docentes: as dificuldades da mediação pedagógica no ensino remoto emergencial. In: VII Congresso Nacional de Educação, 2020, Maceió. Anais. Alagoas. 
Fernandes, F.G., Mollo, R.A., \& Barbosa, F.D. A aplicação de um jogo para motivação do processo de ensino-aprendizagem em cursos de engenharia e ciências exatas. (2020). FERRAZ, Ana Paula do Carmo Marcheti; BELHOT, Renato Vairo. Taxonomia de Bloom: revisão teórica e apresentação das adequações do instrumento para definição de objetivos instrucionais. Gest. Prod., São Carlos , v. 17, n. 2, p. 421-431,, 2010.

FONSECA, W. S.; LIMA, D. S.; LIMA, A. K. F.; NUNES, M. V. A.; BEZERRA, U. H.; SOEIRO, N. S. Analysis of structural behavior of transformer's winding under inrush current conditions. IEEE Transactions on Industry Applications. v. 54, n. 3, p. 2285-2294, 2018. FONSECA, W.S.; SILVA, C. G. ; GOMES, A. S. ; SOUZA, S. C. . Application of the Flipped Classroom, Jigsaw Classroom and PBL methodologies in an Electrical Engineering Course. In: International Conference on Alive Engineering Education 2017, 2017, Rio de Janeiro. ICAEEdu 2017, 2017.

Garbin, Fernanda G. B.; Kampff, Adriana J.C. Educação a distância em tempo de quarentena:Proposta de um curso com a abordagem da sala de aula invertida. In: XLII Congresso Brasileiro de Educação em Engenharia, 2020, Juiz de Fora. Anais. Juiz de Fora. Hutton 2004: D. V. Hutton. Fundamentals of finite element analysis. McGraw-Hill, 2004.

LEITE, B. S. APRENDIZAGEM TECNOLÓGICA ATIVA . Revista Internacional de Educação Superior, Campinas, SP, v. 40, n. 3, p.580-609, set./dez. 2018.

M. N. O. Sadiku, A. Z. Makki and L. C. Agba. A further introduction to finite element analysis of electromagnetic problems, in IEEE Transactions on Education, vol. 34, no. 4, pp. 322329, Nov. 1991.

Martinez, R; Tardelli, E. Estudo de caso sobre o uso da taxonomia de Bloom aplicada a ferramentas virtuais no ensino superior. Revista Brasileira de Ensino Superior, Rio de Janeiro, vol. 4, n. 2, p. 720, Abril-Junho, 2018.

Meeker, D. Finite element method magnetics version 4.2: User's manual. 161 p, 2015 Menezes, C; Bortoli, R. Gamificação: surgimento e consolidação. Revista Comunicação \& Sociedade, São Bernardo do Campo, v. 40, n. 1, p. 267-297, jan./abr. 2018.

Ministério da Educação. Gabinete do Ministro. Portaria ํㅜ 343, de 17 de Março de 2020. Brasília, 2020.

Nascimento, S; Marques, A. A utilização de novas estratégias no ensino de ciências básicas: uma forma de combate à evasão nos cursos de engenharia. Revista Brasileira de Ensino Superior, Rio de Janeiro, vol. 4, n. 2, p. 7-20, Abril-Junho, 2018.

OLIVEIRA, W. L. A.; ARRUDA, G. H. M.; BITTENCOURT, R. A. Uso do método PBL no ensino de arquitetura de computadores. In: XI International Conference on Engineering and Computer Education (ICECE), 2007.

Pavanelo, E.; Lima, R. Sala de Aula Invertida: a análise de uma experiência na disciplina de Cálculo I. Bolema: Boletim de Educação Matemática, 31(58), 739-759, 2017.

PRADO, Ana. Entendendo o aluno do século 21 e como ensinar a essa nova geração. 2015. Disponível em: https://www.geekie.com.br/blog/entendendo-aluno-seculo-21/. Acesso em: 17 de abr. 2021.

Preis, K.; Biro, O.; Buchgraber, G.; Ticar, I. Thermal-electromagnetic coupling in the finite element simulation of power transformers. IEEE Trans. on Magnetics. v. 42. n. 4. p. 9991002. 2006.

Sande, D.; Sande, D. Uso do kahoot como no ensino de microbiologia ferramenta de avaliação e ensino-aprendizagem industrial. HOLOS,Rio Grande do Norte,2021.

Stoev, Bozhidar \& Todorov, George \& Rizov, Plamen \& Pagiatakis, Gerasimos \& Dritsas, Leonidas. (2017). Finite element analysis of rotating electrical machines - An educational approach. 262-269. 10.1109/EDUCON.2017.7942857.

UNESCO. Padrões e Competências em TIC para Professores: diretrizes de implementação. versão 1.0, Unesco,2021. Disponível em: https://unesdoc.unesco.org/ark:/48223/pf0000156209_por. Acesso em: 19 abr. 2021. 
VELOSO, C. H. L. Desenvolvimento de Uma Ferramenta de Ensino da Equação de Laplace Usando Uma Nova Abordagem do Método de Elementos Finitos. CONGRESSO BRASILEIRO DE EDUCAÇÃO EM ENGENHARIA, 41., 2013.

\title{
APPLICATION OF ACTIVE LEARNING METHODOLOGIES IN AN ELECTRICAL ENGINEERING COURSE DURING THE COVID-19 PANDEMIC: INVERTED CLASSROOM, GAMIFICATION AND PBL
}

\begin{abstract}
This article is of a qualitative and quantitative nature and presents the students' perspective regarding the teaching plan adopted in the module of electrical materials of the Electrical Engineering course in the Emergency Remote Teaching (ERE) period at the Federal University of Pará (UFPA), where the collection of these reports occurred through the application of a questionnaire at the end of the article. Methodologies such as the inverted classroom linked to gamification were used, in addition to computer simulations. The resources used for the development of the proposed activities were video-lessons previously shared with the students, thus applying the concepts of inverted classroom, the Kahoot platform, which allowed the creation of a quiz for the gamification of activities and the use of a software for electromagnetic simulation for application of the Project Based Learning (PBL) method. In addition, this study also highlights the potential of this teaching model and shows that the application of these methodologies are valid and alleviate some problems faced by students during the pandemic period caused by COVID-19.
\end{abstract}

Keywords: Flipped classroom, Gamification, Simulations, PBL, Kahoot. 